\title{
CORRELATIONS FOR HEAT TRANSPORT BY NATURAL CONVECTION OF CVLINDRICAL SURFACES SITUATED ONE ABOVE THE OTHER
}

The paper presents a new criterion equation for calculating the Nusselt number for heat transport by natural convection from different numbers of cylindrical surfaces of heating sources. Horizontal cylindrical surfaces are situated one above the other and each of them is independently electrically heated by constant power output of Joule heating. Correlation relationships were derived on the basis of tens of measurements of heat outputs of the system of electrically heated horizontal cylindrical surfaces in a thermostatic chamber under defined conditions. The number of cylindrical surfaces, their distance and heat output to the horizontal cylinder varied during measurements. The derived criterion equation is significantly simpler compared to equations corrected by polynomial regression.

Keywords: Natural convection, cylindrical surfaces one above the other, criterial equations.

\section{Introduction}

Not only when providing heat distribution in buildings but also in many other technical applications especially in electrotechnics when cooling is ensured, heat is transported from oriented heat transfer surfaces by natural convection. The most frequently used oriented heat transfer surfaces are vertical slabs and horizontal cylindrical sources situated one above the other. In most of the so far published contributions the attention has been paid to modifications of the criterial equation for heat transfer by natural convection from an individual cylinder placed individually in space. Experimental experience from visualisation of density fields around oriented heat transfer surfaces [1] and numerical simulation of thermal fields at heat transfer from pipe heat sources by means of the CFD method [2] showed that the flow in the vicinity of horizontal cylindrical surfaces that are situated higher, is intensively influenced by air stream generated by natural convection onto cylindrical surfaces situated lower. Thus all cylindrical surfaces are flown around by flow field which differs significantly from the flow field generated by one individual horizontal cylindrical heat transfer surface. This is why the criterion equation for natural convection from one individual cylindrical surface cannot be used for the system of horizontally oriented heat transfer surfaces situated one above the other. The equation needs to be modified for a bundle of heat transfer surfaces or to find, on the basis of measurements performed in the thermostatic chamber, a new criterion equation for a bundle of pipes. It is also possible to obtain a database of necessary data on the basis of numerical experiments, for example in ANSYS Fluent code.

\section{Natural convection from a horizontal cylinder}

The boundary layer around the horizontal cylinder with a higher temperature than the ambient temperature begins to develop in its bottom area. Its thickness gradually increases until the layer having a stable form is created on the surface (Figs. 1 and 2). The density of the local Nusselt number is, with respect to the thickness of the boundary layer, the highest in the lowest part and the lowest in the upper part of the boundary layer. The flow around the cylindrical surface has a laminar character along the whole circumference with a greater thickness of the boundary layer.

To determine the average Nusselt number along the circumference of the horizontal cylinder where the characteristic dimension is its outer diameter $\mathrm{d}$, a simple relation according to Morgan is often used. It has the following form:

$\overline{N u_{d}}=\frac{\bar{\alpha} d}{\lambda}=C R a_{d}^{n}$,

where:

$\overline{N u_{d}}$ is average Nusselt number,

$\bar{\alpha}$ is heat transfer coefficient $\left[\mathrm{W} / \mathrm{m}^{2} . \mathrm{K}\right]$,

\footnotetext{
* ${ }^{1}$ Milan Malcho, ${ }^{1}$ Jozef Jandacka, ${ }^{2}$ Tadeas Ochodek, ${ }^{2} J a n$ Kolonicny

${ }^{1}$ Department of Power Engineering, Faculty of Mechanical Engineering, University of Zilina, Slovakia

${ }^{2}$ Energy Research Center, VSB - Technical University of Ostrava, Ostrava - Poruba, Czech Republic

E-mail: milan.malcho@fstroj.uniza.sk
} 
$d$ is characteristic dimension [m],

$\lambda$ is coefficient of thermal conductivity of liquid [W/m.K].

$C$ constant and $n$ exponent are different for a range of the Rayleigh criterion number $R a_{d}$.

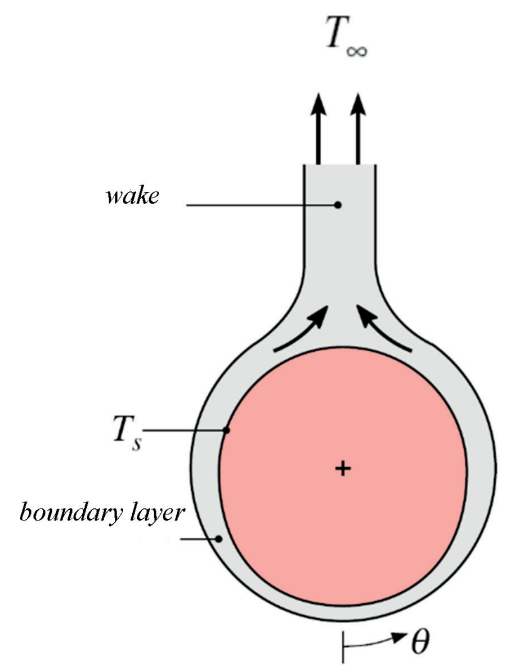

Fig. 1 Development of boundary layer in natural convection from the horizontal cylinder [2]

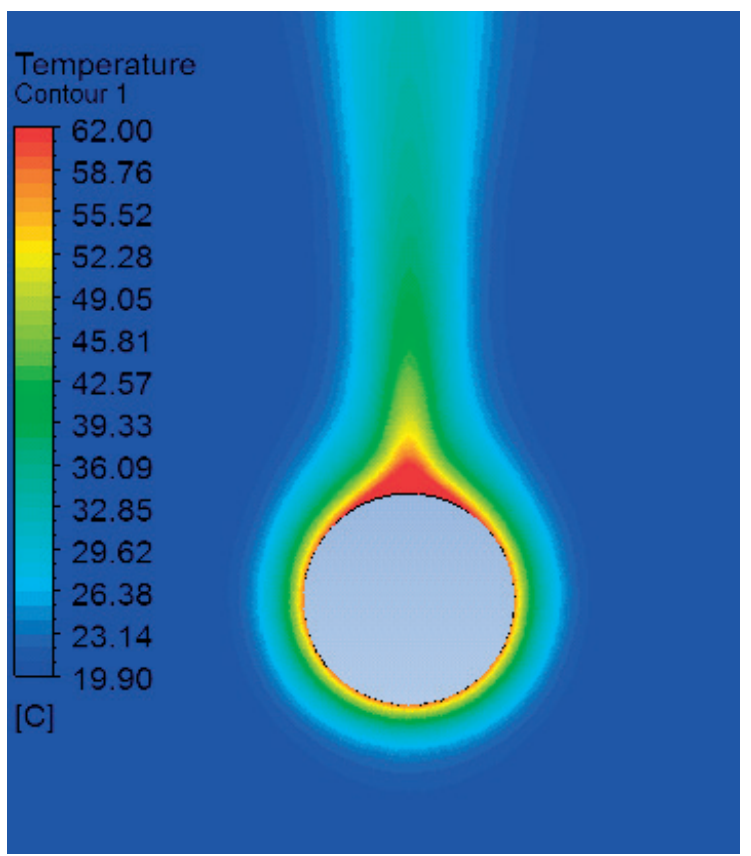

Fig. 2 Visualisation of the thermal field and boundary layer in natural convection from the horizontal cylinder (surface temperature $60.1^{\circ} \mathrm{C}$; ambient temperature $20^{\circ} \mathrm{C}$ ) gathered at simulation computations in ANSYS Fluent [3]
To compute the Nusselt number for a long horizontal cylinder and a wide range of the Rayleigh number, the relation according to Churchiila-Chu [4] is recommended:

$N u_{d}=\left\{0.60+\frac{0.387 R a_{d}^{1 / 6}}{\left[1+(0.559 / P r)^{9 / 16}\right]^{8 / 27}}\right\}^{2}$

pre $10^{-5}<R a_{d}<10^{12}$,

where:

$\operatorname{Pr} \quad$ is the Prandtl number.

For the range $R a_{d}$ of number the following relation holds for natural convection:

$\overline{N u_{d}}=0.36+\frac{0.518 R a_{D}^{1 / 4}}{\left[1+(0.559 / \operatorname{Pr})^{9 / 16}\right]^{4 / 9}}$.

Past publications and research of natural convection from horizontal cylindrical heat transfer surfaces have not mentioned correlation relationships for the Nusselt number of the bundle of heat transfer surfaces which are most frequently used in heating and cooling technology and which would enable complex quantification of the total heat output of the bundle. The influence of pipe distance on the overall heat transfer in natural convection from the pipe bundle was analysed within the experiment by measurements of heat output of a model of a heating source consisting of 10 horizontal pipes having a diameter of $20 \mathrm{~mm}$ and length of $1000 \mathrm{~mm}$ [5].

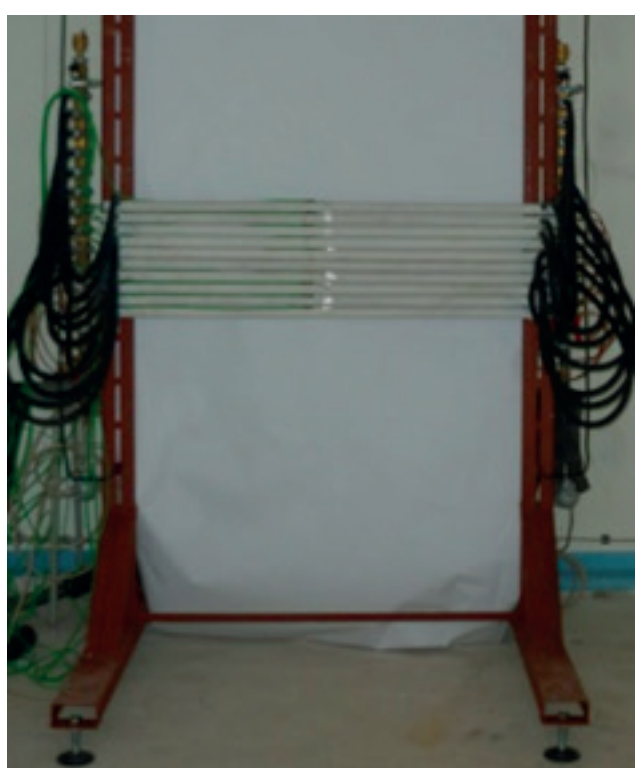

Fig. 3 Arrangement of pipes in a thermostatic chamber at axial istance of pipes $1 D$ [6] 


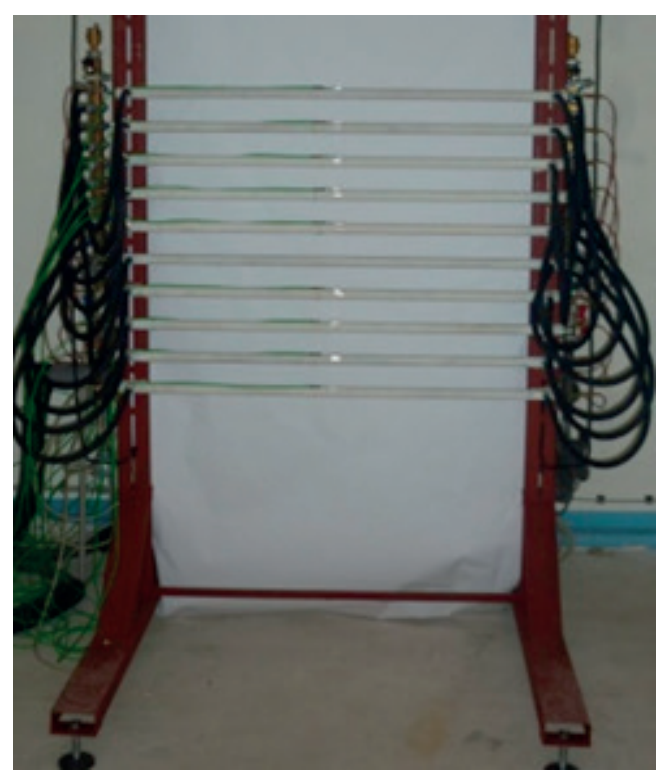

Fig. 4 Arrangement of pipes in a thermostatic chamber at axial distance of pipes $5 \mathrm{D}$ [6]

An objective of analyses was to determine the impact of pipe distance on heat transfer from the pipe system and their impact on the overall heat output of the pipe bundle. The distances among the pipe walls were $0 \mathrm{~mm}$ (Fig. 3), $10 \mathrm{~mm}, 20 \mathrm{~mm}$ and $40 \mathrm{~mm}$ (Fig. 4). Measurements were done at temperature gradients $55{ }^{\circ} \mathrm{C} / 45$ ${ }^{\circ} \mathrm{C}, 75{ }^{\circ} \mathrm{C} / 65{ }^{\circ} \mathrm{C}, 85^{\circ} \mathrm{C} / 75{ }^{\circ} \mathrm{C}$, the ambient temperature of 20 ${ }^{\circ} \mathrm{C}$. The measurement was compared with a CFD mathematical model of heat transport from the system of pipes situated one above the other.

An extensive set of numerical experiments in the field of heat transport by natural convection from oriented heat transfer surfaces was performed by Kapjor [6] and experiments were done by Annunziata D'Orazio [7]. From the gathered material Kapjor created a new criterion relation for the computation of the Nusselt number for natural convection from " $n$ " horizontally arranged cylindrical surfaces situated one above the other by means of polynomial regression. In ANSYS Fluent code tens of heat transport simulations were performed from ten pipes having an outer diameter of $20 \mathrm{~mm}$ situated one above the other. The wall temperature was $30{ }^{\circ} \mathrm{C}, 45{ }^{\circ} \mathrm{C}, 60{ }^{\circ} \mathrm{C}, 75{ }^{\circ} \mathrm{C}, 90{ }^{\circ} \mathrm{C}, 105{ }^{\circ} \mathrm{C}$ and ambient temperature $20{ }^{\circ} \mathrm{C}$. It was expected that the heat output in natural convection from " $\mathrm{n}$ " horizontal pipes situated one above the other is dependent on dimensionless spacing $H / D$ as well as on dimensionless variable $T_{\alpha} / T_{s}$. At approximation the least square method for the function of two variables was used. Approximation polynomial regressions of higher orders $(n>5)$ were computed from functional dependencies of the Nusselt number of the bundle of horizontal pipes in ratio $H / D$ and $T_{\alpha} / T_{s}$.

Analytical solutions and experiments show that heat transfer by natural convection from any surface depends on the surface geometry, on its orientation as well as on distribution of temperature on the surface and also on thermo physical characteristics of liquid.

Reference temperature, from which physical characteristics needed for computation are determined, is the average temperature of the boundary layer:

$T_{f}=\left(T_{S}+T_{\infty}\right) / 2 \quad\left[{ }^{\circ} \mathrm{C}\right]$.

The flow of liquid in natural convection can be unstable due to the occasionality of turbulence. This instability is caused by flow disturbances which gradually get stronger and laminar flow becomes turbulent. As already mentioned, the flow character in natural convection determines the criterion of the Rayleigh's Ra.

\section{Measurement and thermal analysis of horizontal heating pipes situated one above the other}

The measurement of heat flows of the bundle of horizontal heat transfer surfaces was performed in a thermostatic chamber. During measurements, the temperature of the chamber inner walls was controlled so that the reference value of air temperature in the chamber, which was measured by Vernon resistance thermometer PT-100 DIN 1/5, would be stationary $20 \pm 0.5^{\circ} \mathrm{C}$.

The thermostatic chamber is controlled by Siemens Systematic S7-300. Visualization D2000 is programmed to the regulation system to visualise the situation in the thermostatic chamber. It provides a fully automated control of the chamber and helps to achieve equilibrium conditions at different measurement requirements within the range of measurability range.

Other experiments performed in the thermostatic chamber were measurements of thermal outputs from various systems of vertical arrangement of horizontal heated cylinders placed one above the other with an objective to design a new form of criterion equation for the computation of the Nusselt number of such a bundle. To obtain output and thermal parameters necessary for the creation of a new criterion relationship on the basis of which it would be possible to quantify the thermal output from " $n$ " vertically arranged horizontal heated cylinders placed one above the other in natural convection, the measurements in the thermostatic chamber together with simulation analyses in ANSYS Fluent were performed gradually on three, five and ten horizontal cylinders situated one above the other. The principle and method of measurement were similar to those used for measurement and analysis of thermal output from one heated horizontal cylinder.

The measurement in thermostatic chamber consisted of the measurement of thermal and output parameters from three, five and ten electrically heated horizontal cylinders placed one above the other.

Ten, five and three heated cylinders were horizontally fixed on the stand in the thermostatic chamber (Fig. 5). During 

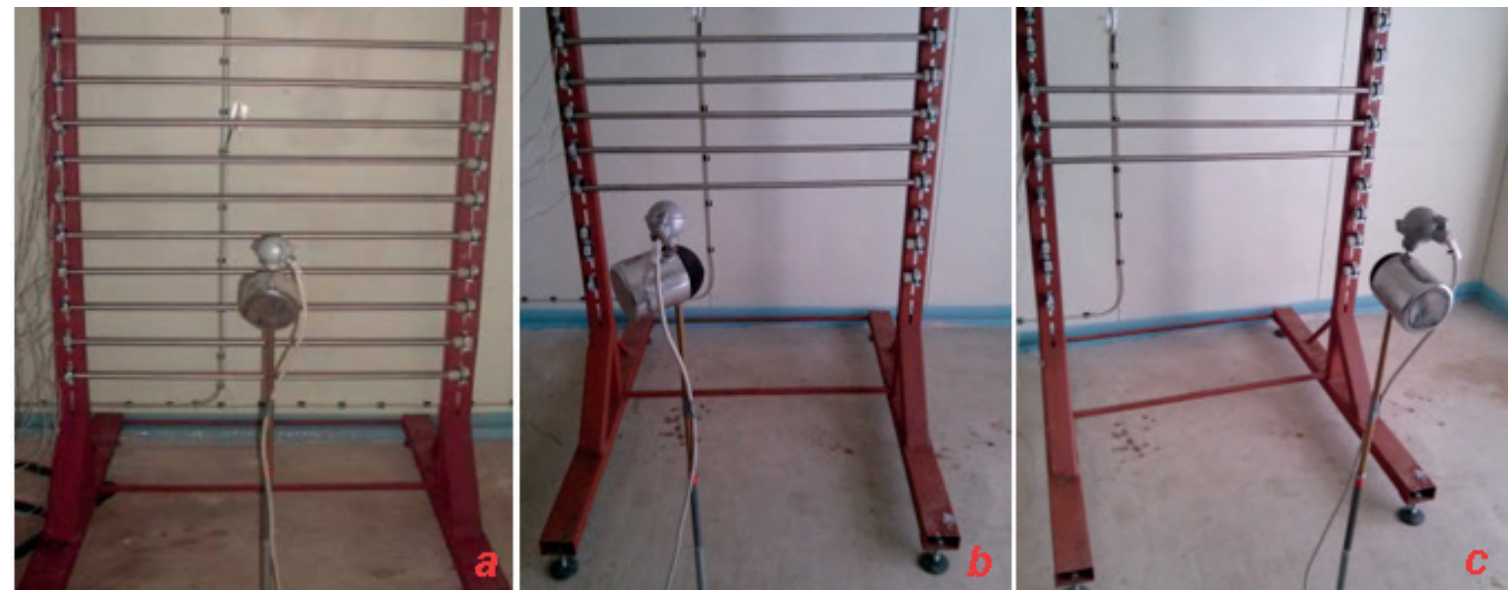

Fig. 5 The fixing of a) ten, b) five and c) three horizontal heated cylinders on the stand in thermostatic chamber

measurement each cylinder was heated by the same electric output. The distance among individual cylinders gradually changed from $20 \mathrm{~mm}$ to $100 \mathrm{~mm}$, with a step of $20 \mathrm{~mm}$. The changing distance was defined by ratio $H / D$. Ratio $H / D$ represents a dimensionless distance among the cylinders (Fig. 6). The temperatures, the cylinders achieved after the supplied equal electric output, were measured.

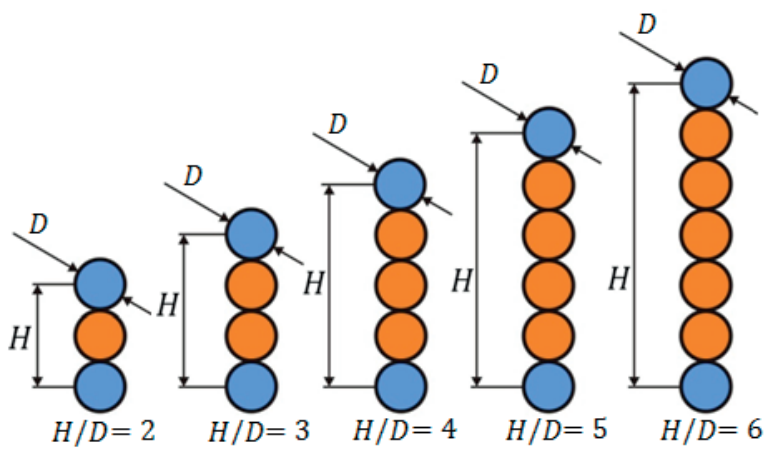

Fig. 6 Distance among individual cylinders in ratio $H / D$

Having connected all the heated cylinders to power sources, thermocouples to the central measuring station and having set all distances among individual cylinders, the measurements started. An objective of the measurements was to record surface temperatures of individual heated cylinders which changed due to changing distances among the individual cylinders with the supplied constant electric input. The reason why the experimental measurement was performed on bundles of ten, five and three horizontal heated cylinders is to obtain sufficient numbers of surface temperature values of individual cylinders for criterion numbers. It is obvious that at existing arrangements of pipe systems various thermal fields originate in the vicinity of the bundles. Due to thermal fields generated when arranging given bundles of cylinders, the surface temperatures of individual cylinders also change. The values are different for a bundle of ten, five or three cylinders. This way a greater number of surface temperatures is obtained - data highly important for further analyses and final computations.

As obvious from the values of individual measurements shown in the previous tables, the change of distance among individual cylinders results in outstanding change of surface temperatures of horizontal heated cylinders situated one above the other. When the distance among cylinders is $20 \mathrm{~mm}$ and $40 \mathrm{~mm}$ (ratio $H / D=1$ and $H / D=2$ ), the surface temperatures of the cylinders increase. This growth of temperature is caused by the fact that a thermal field is formed in the vicinity of the cylinder, which influences the cylinder placed above; thus in the vicinity of the cylinder placed above a thermal field with a higher temperature is formed, which causes the increase of its surface temperature at the constant electric input. Changing the ratio $H / D=3$, at which the distance among individual cylinder gets the value of $60 \mathrm{~mm}$, the growth of the surface temperature is lower as there is no more significant impact on the individual cylinders and the surface temperatures of cylinders do not tend to increase. From the values of surface temperatures of cylinders placed at the distance of $100 \mathrm{~mm}$ it is obvious that there is no influence of thermal fields from the heated cylinders situated above them. The heated cylinders thus obtain temperatures corresponding to the values which were recorded when measuring one heated cylinder.

Generated thermal fields near the individual bundles of cylinders that originate in heat transfer from their surfaces to environment and their interaction result in the already mentioned growth of surface temperature of individual cylinders. This phenomenon can be better seen in Fig. 7 which shows chosen visualisations of thermal fields gathered from simulation analyses from ANSYS Fluent around three, five and ten heater horizontal cylinders situated one above the other. 


\section{COMMNICOIIONS}

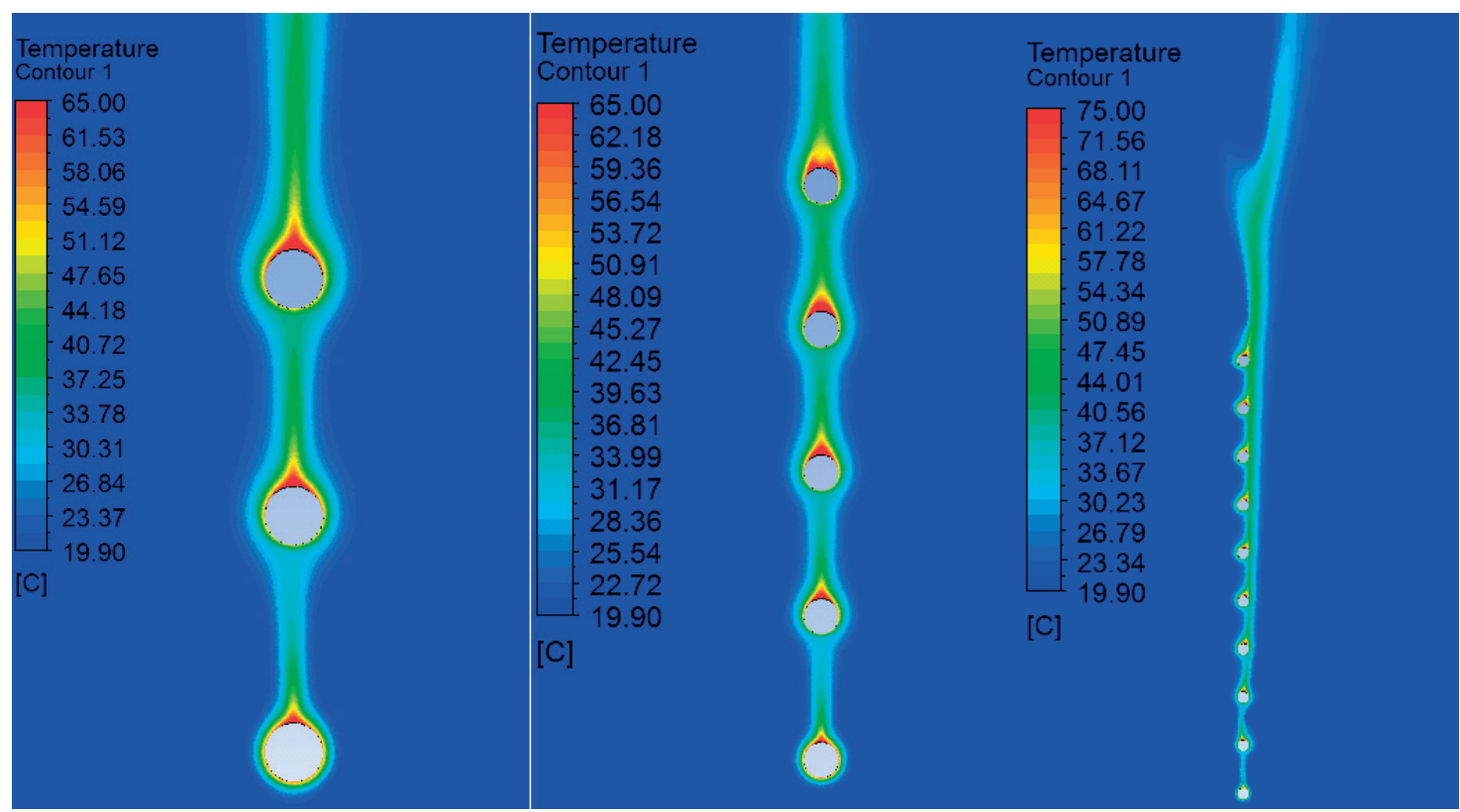

Fig. 7 CFD visualisations of thermal fields around bundles of heated horizontal cylinders $(3,5,10)$ situated one above the other, with the initial temperature of a heated cylinder $60^{\circ} \mathrm{C}$ at the ambient temperature of $20^{\circ} \mathrm{C}$ and ratio $H / D=4$

The new criterion relation for the Nusselt number, according to which thermal output can be quantified from " $n$ " vertically arranged horizontal pipes placed one above the other in natural convection, was determined on the basis of data gathered from experimental measurements, simulation computations and analyses with the help of known mathematical methods. The criterion relation was formed on the basis of dimensional analysis with the help of a multiple linear regression.

\section{Processing and analysis of data for creation of criterion relation}

To create a new criterion relation for computing the Nusselt number from " $n$ " vertically arranged horizontal pipes placed one above the other, processed and analysed data gathered from experimental measurements, simulation analyses and mathematical computations are used.

As already mentioned, the proposed criterion relation will be formed on the basis of dimensional analysis from measured and computed data with the help of a multiple linear regression in Microsoft Excel. In a general case, it will be an equation expressing physical dependence of $n$ chosen relevant dimensionless quantities $x_{1}, x_{2}, x_{3}$ and $x_{4}$ in the form

$y=b_{0} \cdot x_{1}^{b_{1}} \cdot x_{2}^{b_{2}} \cdot x_{3}^{b_{3}} \cdot x_{4}^{b_{4}}$,

where

$y$ is an estimated value of the Nusselt number,

$x_{1}-x_{n}$ are values of independent variables, and

$b_{0}-b_{4}$ are regression coefficients.
Having logarithmized equation (5), it obtains the form (6)

$\log y=\log b_{0}+b_{1} \log X_{1}+b_{2} \log X_{2}+$

$+b_{3} \log X_{3}+b_{4} \log X_{4}$

or (7)

$z=a_{0}+b_{1} y_{1}+b_{2} y_{2}+b_{3} y_{3}+b_{4} y_{4}$

where the form is more suitable for the multi parametric linear regression. In its application various physical and geometric parameters were used as parameters $X_{1}, X_{2}, X_{3}$ and $X_{4}$.

The following 4 dependent variable dimensionless quantities are assessed:

- changing distance among individual pipes - ratio - $H / D$,

- number of horizontal cylindrical surfaces - $n$,

- Rayleigh number $(R a=G r \cdot P r)$ that includes changing temperatures of the wall temperatures to the ambient temperature through defining the average temperature difference $\Delta t_{s t r}$

- ratio of the ambient Prandtl number for the ambient noninfluenced by temperature and the Prandtl number for surface temperature of one pipe - $P r / P r_{s}$ whose value influences the thickness of boundary layers.

The regression constant $b_{0}$ and regression coefficients $b_{1}-b_{4}$ were obtained through specific functions for multi parametric regression in a table processor MICROSOFT EXCEL. The values of standard deviation $\sigma$ and correlation index $R$ were also set. The standard deviation simply gives the average difference between a computed and real value of the Nusselt number. The reliability 
of computed results obtained through correlation is given by the value of correlation index $R$. If this value exceeds 0.7 , the results are generally acceptable; if this value exceeds 0.8 , the results are good; if this value is higher than 0.9 , the results are excellent.

After the analysis of the achieved results and their consequent processing we came to conclusion that the value of the Nusselt number from " $n$ " vertically arranged horizontal pipes placed one above the other is mainly dependent on the changing distance among individual pipes, that is, on a dimensionless parameter, on the ratio $H / D$, on the number of heating pipes $n$, and also on the change of individual pipes situated one above the other. This change of surface temperatures is characterised by the average value of temperature difference $\Delta t_{\text {str }}$ obtained from all the heating pipes. The values $\Delta t_{s t r}$ are obtained from individual types of arrangements, from bundles of three, five and ten heating pipes. The ratio $\left(\mathrm{Pr} / \mathrm{Pr}_{\mathrm{s}}\right)$ contains the influence of temperature taken on the first pipe wall on the heat transfer from the bundle of pipes in which the value $P r$ was determined from ambient parameters and the value $P r_{s}$ from the temperature of the first bottom pipe wall.

Owing to heat transfer by natural convection, the determining parameter was the criterion number $R a=G r . P r$ whose values were computed similarly as in the case of natural convection from one pipe at $R a=G r \cdot P r<10^{8}$.

The multiple linear regression was done for two types of obtained values:

- For values obtained from simulation computations in ANSYS Fluent,

- For values obtained from experimental measurements in the thermostatic chamber.

From the values obtained from simulation computations in ANSYS Fluent, we processed data by the multiple regression in Microsoft Excel. On their basis we created the equation which, having been delogarithmized, gained the form

$N u=32.25 \cdot(H / D)^{0.16} \cdot n^{-0.03} \cdot \operatorname{Ra}^{-0.27} \cdot\left(\operatorname{Pr}_{P} \operatorname{Pr}_{s}\right)^{-65.5}$

Constant $\mathrm{b}_{0}$, regression coefficients $b_{1}-b_{4}$, standard deviation $\sigma$ and correlation index $R$ have following values:

\begin{tabular}{|c|c|c|c|c|c|c|}
\hline $\boldsymbol{b}_{\boldsymbol{0}}$ & $\boldsymbol{b}_{\boldsymbol{1}}$ & $\boldsymbol{b}_{2}$ & $\boldsymbol{b}_{\mathbf{3}}$ & $\boldsymbol{b}_{\boldsymbol{4}}$ & $\boldsymbol{R}$ & $\boldsymbol{S}$ \\
\hline 32.25 & 0.16 & -0.03 & -0.27 & -65.5 & 0.9101 & 0.0212 \\
\hline
\end{tabular}

Figures $8 \mathrm{a}-8 \mathrm{~d}$ show comparison of values of the Nusselt number computed according to the obtained equation (8) with the values computed from simulation results for individual bundles of pipes.

In a similar way we did computation from the values obtained from measurements on experimental device in the thermostatic chamber. The computation was done in Microsoft Excel through the multiple linear regression.

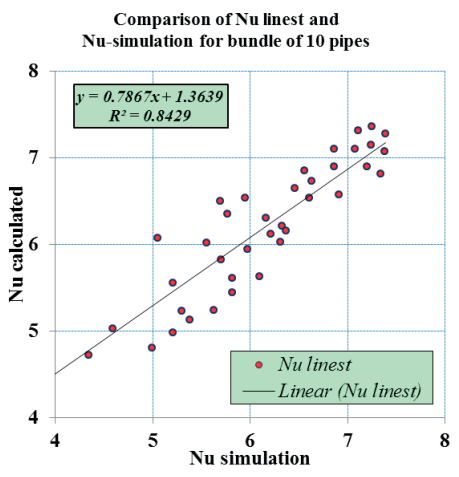

a)

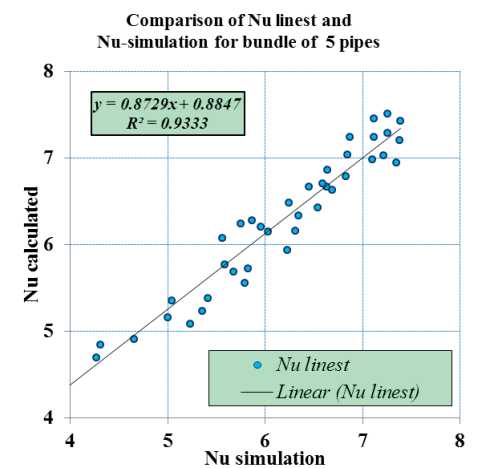

b)

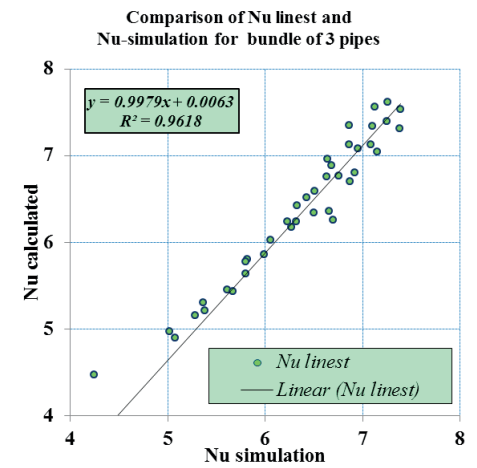

c)

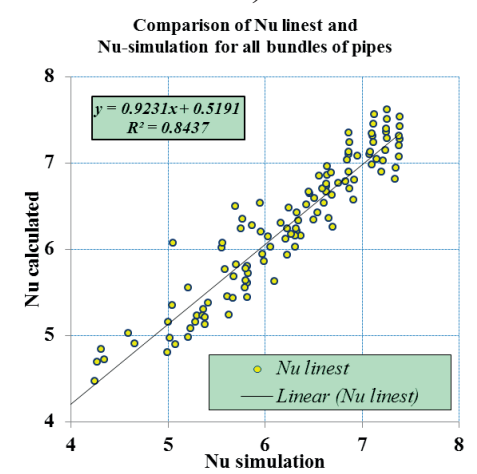

d)

Fig. 8 Comparison of computed and simulated values of the Nusselt number for bundles of ten, five, three and all heated cylinders 
The resultant criterion equation for natural convection from the bundle of pipes has the form

$$
N u=4.705 \cdot(H / D)^{0.14} \cdot n^{-0.02} \cdot \operatorname{Ra}^{-0.03} \cdot\left(\operatorname{Pr} / \operatorname{Pr}_{s}\right)^{-29}
$$

For the constant $b_{0}$, regression coefficients $b_{1}-b_{4}$, standard deviation $\sigma$ and correlation index $R$ following values hold:

\begin{tabular}{|c|c|c|c|c|c|c|}
\hline $\boldsymbol{b}_{\boldsymbol{0}}$ & $\boldsymbol{b}_{\boldsymbol{1}}$ & $\boldsymbol{b}_{2}$ & $\boldsymbol{b}_{\mathbf{3}}$ & $\boldsymbol{b}_{4}$ & $\boldsymbol{R}$ & $\boldsymbol{S}$ \\
\hline 4.705 & 0.14 & -0.02 & -0.03 & -29 & 0.958 & 0.0117 \\
\hline
\end{tabular}

Figures $9 \mathrm{a}-9 \mathrm{~d}$ show comparison of values of the Nusselt number computed according to the obtained equation (9) with the values computed from measured results for individual bundles of pipes.

\section{Conclusion}

From the performed analyses follows that the criterion equation for a bundle of horizontal pipes regularly situated vertically one above the other, proposed on the basis of a set of measured data shows a better correlation than the criterion equation determined from the data obtained from a numerical experiment by the CFD method.

A cause may be that the CFD model of natural turbulence captures only one shape of the flow field above the pipes (an image of current distribution of flow and thermal field). These fields are markedly non-stationary especially in the upper part of the bundle and change their shape so that the CFD method does not catch their average parameters in time. When measuring determining parameters, the temperatures of surfaces and air are naturally averaged in time due to thermal accumulation of pipes and sensors. Further averaging can be achieved through processing a greater number of data recorded by the central measuring station to a table process.

Comparing the criterion equation for heat transfer in natural convection on an individual horizontal pipe proposed according to Michejev in the form

$$
\begin{aligned}
& N u_{1}=0.5(G r \cdot \operatorname{Pr})^{0.25} \cdot\left(\operatorname{Pr} / \operatorname{Pr}_{s}\right)^{0.25} \\
& \text { for } 10^{3}<G r . P r<10^{6}
\end{aligned}
$$

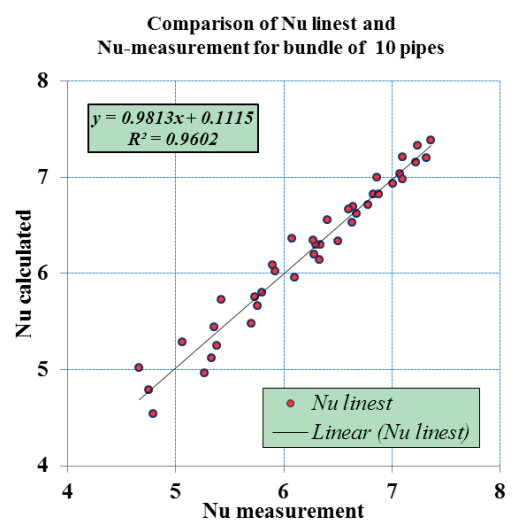

a)

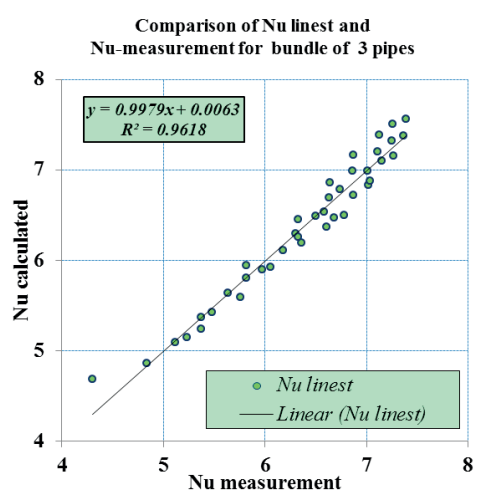

c)

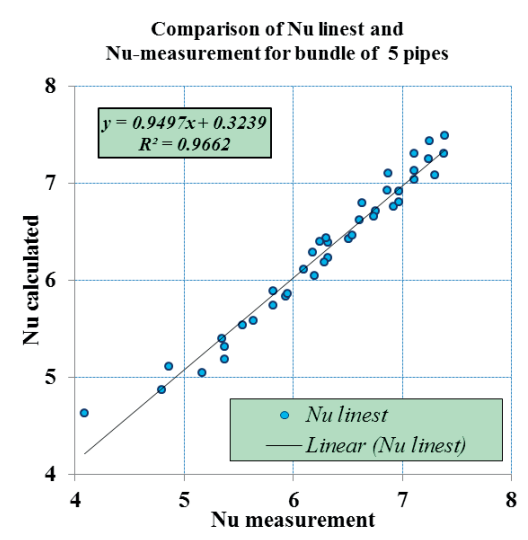

b)

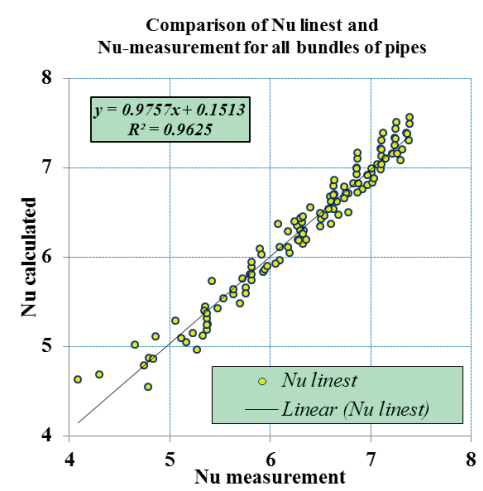

d)

Fig. 9 Comparison of computed and measured values of the Nusselt number for bundles of ten, five, three and all heated cylinders 
or a proposed relation according to Morgan in the form

$$
N u_{1}=0.48(R a)^{0.25} \text { for } 10^{4}<G r \cdot \operatorname{Pr}<10^{7}
$$

then for heat transfer of the bundle of horizontal cylinders vertically arranged one above the other a criterial equation can be proposed in the form:

$$
N u_{\text {bundle }}=N u_{1} \cdot f\left\{(H / D), n, R a,\left(\operatorname{Pr} / P r_{s}\right)\right\}
$$

where for the relation of the first pipe according to Morgan, the resultant equation has the form

$$
\begin{aligned}
& N u_{\text {bundle }}=N u_{1} \cdot 9.8 \cdot(G r \cdot P r)^{-0.28} \cdot(H / D)^{0.14} . \\
& \cdot n^{-0.02} \cdot\left(\operatorname{Pr} / \mathrm{Pr}_{s}\right)^{-29}
\end{aligned}
$$

The obtained forms of criterion equation are significantly simpler than equations with polynomial corrections at a good approximation of the Nusselt number determined from experimental measurements.

\section{Acknowledgement}

This paper has been elaborated in the framework of the project "Support of research and development in the MoravianSilesian Region 2013 DT 1 - International research teams“ (02613/2013/RRC). Financed from the budget of the MoravianSilesian Region.

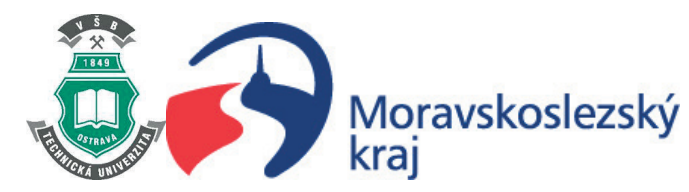

\section{References}

[1] MARTYNENKO, O. G., KHRAMTSON, P. P.: Free - Convective Heat Transfer. Springer : New York, 2005, ISBN - 10 3-540-25001-8.

[2] GRESSAK, T., KAPJOR, A., HUZVAR, J., JANDACKA, J., MALCHO, M.: Influence of Design Parameters of Floor Convector on its Performance. Intern. Congress on Engineering and Technology - ICET, June 2013, Dubrovnik, 2013, ISBN 978-80-87670-08-8, pp. 153-158.

[3] INCROPERA, F. P., DEWITT, D. P, BERGMAN, T. L, LAVINE, A.: Fundamentals of Heat and Mass Transfer. $6^{\text {th }}$ ed., John Wiley : New York, 2007.

[4] CHURCHILL, S. W., CHU, H. H. S.: Correlating Equations for Laminar and Turbulent free Convection from a Horizontal Cylinder. Int. J. Heat Mass Transfer, 18, 1049-1053, 1975.

[5] SMATANOVA, H., JANDACKA, J., MALCHO, M., KAPJOR, A.: The Influence of Construction of a Ladder Heat Source on its Thermal Output (in Slovak), Strojarstvo-Strojirenstvi, 6, 2009, extra edition, Kosice, p. 244, ISSN 1335-2938.

[6] SMATANOVA, H., KAPJOR, A., HUZVAR, J., GRESSAK, T.: Determination of the Maximum Heat Output of a Pipe Heat Source HDR 12 by a CFD Method (in Slovak), 32 ${ }^{\text {nd }}$ Session of Departments of liquid mechanics and thermomechanics, June 2013, Tatranska Lomnica : Zilina : Zilinska univerzita, 2013, ISBN 978-80-554-0715-9, pp. 73-76.

[7] D ORAZIO A., FONTANA L.: Experimental Study of Free Convection from a Pair of Vertical Arrays of Horizontal Cylinders at Very Low Rayleigh Numbers. Intern. J. of Heat and Mass Transfer, vol. 53, No. 15-16, July 2010, pp. 3131-3142. Available at: <http://www.sciencedirect.com/science/article/pii/S001793101000147X ISSN: 0017-9310. 